\title{
Comparison of Two Post-Transplant Predictive Indexes: Day 100 is a Better Time-Point for Response Evaluation after Autologous Stem Cell Transplantation in Multiple Myeloma: A Retrospective Study
}

\author{
Ma'koseh M*, Sa'deh S, Halahleh K, Abu-Jazar \\ H, Dahabreh L, Khattab E, Abu Shanap M, Al- \\ Shyoukh A, Alfar R, Hashem H, Najjar R, Da'na \\ $\mathrm{W}$ and Tbakhi $\mathrm{A}$ \\ King Hussein Cancer Center, J ordan \\ *Correspondling author: Ma'koseh M, King Hussein \\ Cancer Center, Queen Rania Al-Abdulla Street, Amman \\ 11941, J ordan
}

Received: September 09, 2020; Accepted: October 05, 2020; Published: October 12, 2020

\begin{abstract}
In Multiple Myeloma (MM), response to High-Dose Chemotherapy (HDC) and Autologous Stem Cell Transplant (ASCT) has important prognostic and therapeutic implications. Best timing for response evaluation after ASCT is not well studied. Our study evaluated the correlation between response on day 30 and day 100 after ASCT with Progression Free Survival (PFS) and Overall Survival (OS) in $119 \mathrm{MM}$ patients. Median follow-up was 39.8 months. Complete Response (CR) was achieved in $53.8 \%$ and $55.5 \%$ of patients on D 30 and D 100 , respectively. On D30, there was no significant difference in PFS or OS in CR vs. no CR group (35.4 vs. 22.1 months, p: 0.058) and (92.6 months vs. not reached p: 0.96$)$ respectively nor in responders (R) vs. Non-Responders (NR) group (97.8 vs. 47.1 months p: 0.08) and (30.2 vs. 18.9 months, p: 0.09) respectively. While on D100, PFS was significantly better in CR vs. no CR group (33.8 vs. 18.1 months, p: 0.0047) as well as in R vs. NR (30.6 vs. 16.9 months $p$ : 0.015). However, OS was not better in either (92.6 vs. 52.1 months p: 0.46) and (92.6 months vs. not reached p: 0,88 ) respectively. In conclusion, after HDC and ASCT for MM, we recommend doing response evaluation on D100 rather than D30 as it better correlates with PFS. Further studies are required to confirm this finding in the era of consolidation and maintenance treatment.
\end{abstract}

Keywords: Multiple myeloma; High dose chemotherapy; Response

\section{Introduction}

Following induction therapy, High Dose Chemotherapy (HDC) and Autologous Stem Cell Transplant (ASCT) has been the mainstay of treatment of transplant eligible Multiple Myeloma (MM) patients, given that multiple studies confirmed that it prolongs Progression Free Survival (PFS) and possibly Overall Survival (OS) [1-4].

Depth of response after HDC and ASCT has important prognostic as well as therapeutic implications. Multiple studies have shown survival advantage from achieving and maintaining Complete Response (CR) after HDC and ASCT [5-7]. In a meta-analysis of 21 studies including 4,990 patients, significant associations between maximal response and survival outcomes were demonstrated [5].

In addition, response to ASCT may play a role in deciding to proceed to tandem ASCT. In the trial conducted by Attal et al., responding patients not achieving Very Good Partial Response (VGPR) after the first ASCT, benefited from tandem ASCT [1].

The best timing for response evaluation after ASCT is not well studied. In some trials, evaluation was done on 100 days post ASCT $[2,6]$ while in other trials, evaluation was done before [8-11].

In our center, we were routinely evaluating the response on 30 and 100 days after ASCT.
To evaluate which time-point for response evaluation that better predicts outcomes, we retrospectively reviewed the results of patients who received HDC and ASCT in our center and examined the correlation between outcomes and response evaluation results on day 30 (D30) and day100 (D100).

\section{Patients and Methods}

We retrospectively analyzed medical records of patients diagnosed with multiple myeloma and received HDC and ASCT at King Hussein Cancer center in Jordan from January 2008 till December 2015.

The following data were retrieved from patients' charts and electronic medical records: Age, gender, initial renal function, stage on time of diagnosis (based on B-2 microglobulin and albumin), and induction treatment given. Results of Serum Protein Electrophoresis (SPEP), Urine Protein Electrophoresis (UPEP) and Free Light Chain (FLC) on diagnosis, before ASCT, on D30 and on D100 after transplant were used to evaluate response to treatment.

Response evaluation was according to the International Myeloma Working Group (IMWG) Uniform Response Criteria [12]. Correlation between response and outcomes (PFS and OS) was examined for D 30 and D 100 results. Comparison was done between patient who achieved CR or VGPR vs. no CR (Partial Response (PR), Stable Disease (SD) or Disease Progression (DP)) and between those who achieved a response (CR, VGPR or PR) vs. no response (SD or
Ann Hematol Oncol - Volume 7 Issue 8 - 2020 ISSN : 2375-7965 | www.austinpublishing group.com Ma'koseh et al. (C) All rights are reserved
Citation: Ma'koseh M, Sa'deh S, Halahleh K, Abu-Jazar H, Dahabreh L, Khattab E, et al. Comparison of Two Post-Transplant Predictive Indexes: Day 100 is a Better Time-Point for Response Evaluation after Autologous Stem Cell Transplantation in Multiple Myeloma: A Retrospective Study. Ann Hematol Oncol. 2020; 7(8): 1314. 
Table 1: Patients characteristics.

\begin{tabular}{|c|c|}
\hline Patients, $\mathrm{n}$ & 119 \\
\hline \multicolumn{2}{|l|}{ Age (years) } \\
\hline Range & 33-66 years \\
\hline Median & 52 years \\
\hline \multicolumn{2}{|l|}{ Gender, n (\%) } \\
\hline Male & $78(65.5 \%)$ \\
\hline Female & $41(34.5 \%)$ \\
\hline \multicolumn{2}{|l|}{ Type, n (\%) } \\
\hline $\lg G$ & $76(63.8 \%)$ \\
\hline $\lg A$ & $14(11.8 \%)$ \\
\hline Light chain & $29(24.4 \%)$ \\
\hline \multicolumn{2}{|l|}{ ISS stage, $\mathrm{n}(\%)$} \\
\hline 1 & $31(26.1 \%)$ \\
\hline II & $49(41.2 \%)$ \\
\hline III & $36(30.3 \%)$ \\
\hline Not known & $3(2.5 \%)$ \\
\hline \multicolumn{2}{|l|}{ Renal function on diagnosis, $\mathrm{n}(\%)$} \\
\hline Normal & $82(68.9 \%)$ \\
\hline Abnormal & $24(20.1 \%)$ \\
\hline Not known & $13(11 \%)$ \\
\hline \multicolumn{2}{|l|}{ First line treatment, $\mathrm{n}(\%)$} \\
\hline Novel agents, & $114(95.7 \%)$ \\
\hline Chemotherapy & $5(4.3 \%)$ \\
\hline \multicolumn{2}{|l|}{ Number of treatment lines before transplant, $\mathrm{n}(\%)$} \\
\hline 1 & $88(73.9 \%)$ \\
\hline 2 & $27(22.7)$ \\
\hline 3 & $4(3.4 \%)$ \\
\hline \multicolumn{2}{|l|}{ Response to induction treatment before transplant, $\mathrm{n}(\%)$} \\
\hline CR or VGPR & $49(41.2 \%)$ \\
\hline PR & $65(54.6 \%)$ \\
\hline SD & $5(4.2 \%)$ \\
\hline
\end{tabular}

Abbreviations: CR: complete response, VGPR: very good partial response, PR: partial response, ISS: International Staging System for myeloma.

DP). Survival curves were plotted by the Kaplan-Meier method and compared by the Log-Rank test.

\section{Results}

\section{Patient's characteristics}

119 patients were included. Median age on time of diagnosis was 52 years. According to International Staging System (ISS) for myeloma [13], 31 (26\%) had stage I, 49 (41.2\%) had stage II and 36 (30.3\%) had stage III. 88 (73\%) patients received only one line of treatment before transplant while the remaining patients received more than one line. Initial treatment in 114(95.7\%) included novel agents (thalidomide, bortezomib and lenalidomide). Median follow up was 39.8 months add patient characteristics are detailed in table 1 .

Response evaluation: Before transplant, 49 (41.2\%) achieved CR or VGPR, while 65 (54.6\%) had PR and 5 (4.2) had SD. 30 days after ASCT, CR or VGPR was found in 65 (54.6\%), 26(21.8\%) had PR, 19 (16\%) had SD and 8 (6.7\%) had DP.

On day 100, response was CR in 66 (55.5\%), PR in 18 (15.1\%), SD in $18(15.1 \%)$ and disease progression in $15(12.6 \%)$.

When compared to D30, D100 the responses were better in 20 $(16.8 \%)$, worse in $19(16 \%)$ and the same in $80(67.2 \%)$ patients.

Survival: Median progression free survival was 30 months. On D 30, PFS was better in patient who achieved CR vs no CR (35.44 months vs. 22.1 months) but the $\mathrm{P}$ value was marginally significant (P: 0.058) (Figure 1), while on D 100, PFS was significantly better in patient who achieved CR vs. no CR (33.87 months vs. 18.16 months,

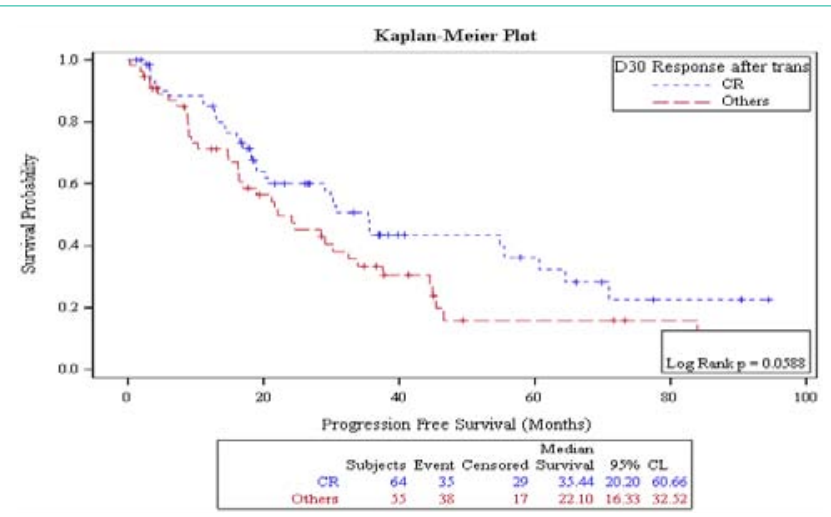

Figure 1: Day 30 response: PFS in patients achieving CR vs. no CR.

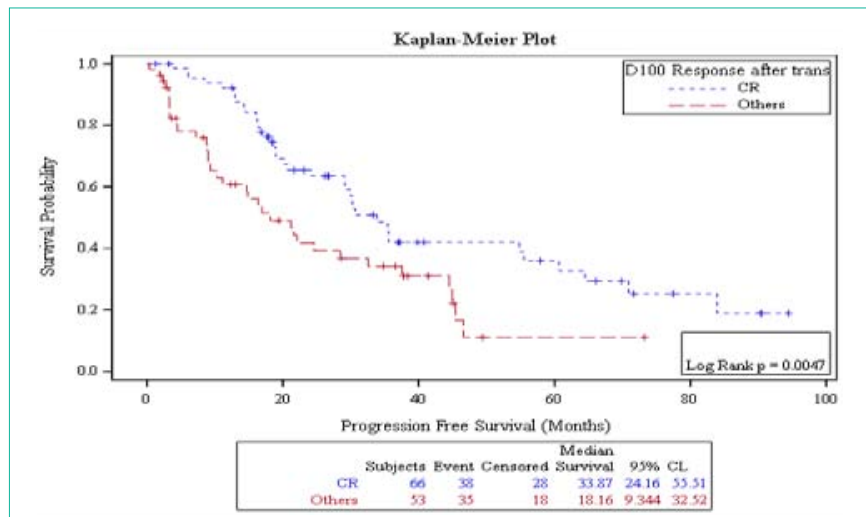

Figure 2: Day 100 response: PFS in patients achieving CR vs. no CR.

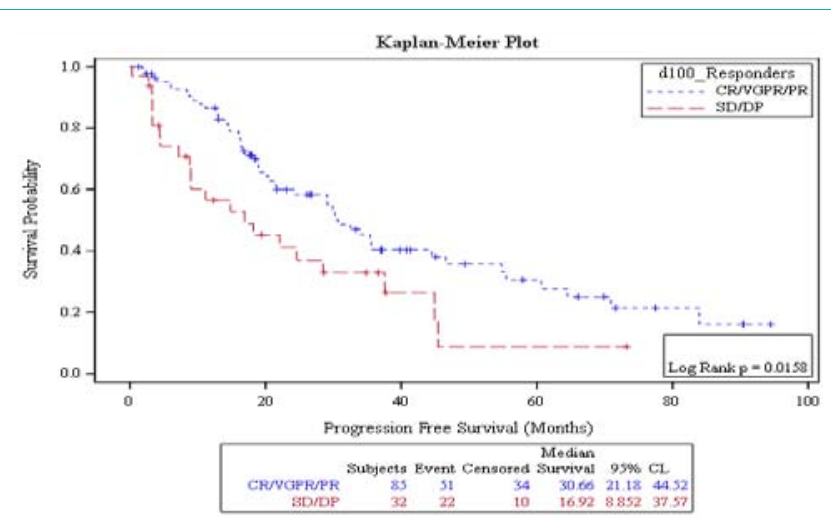

Figure 3: Day 100 response: PFS in patients achieving Response vs. no response.

P: 0.0047) (Figure 2). Also, on D100 PFS was significantly better in patients who achieved a response $v s$. no response (30.66 months $v s$. 16.92 months, P: 0.0158 ) (Figure 3) but not on D30 (30.26 months vs. 18.98 months P: 0.08) (Figure 4).

There was no statistically significant difference in OS in patients who achieved CR vs. no CR neither on day 30 (92.69 months vs. not reached, P: 0.968) (Figure 5) nor on day 100 (92.6 months vs. 52.16 months, P: 0.453) (Figure 6) evaluations. Also, overall survival wasn't significantly different between responders $v s$. non responders on both times points: on D30: 97.8 months vs. 47.1 months P: 0.09 (Figure 7) 


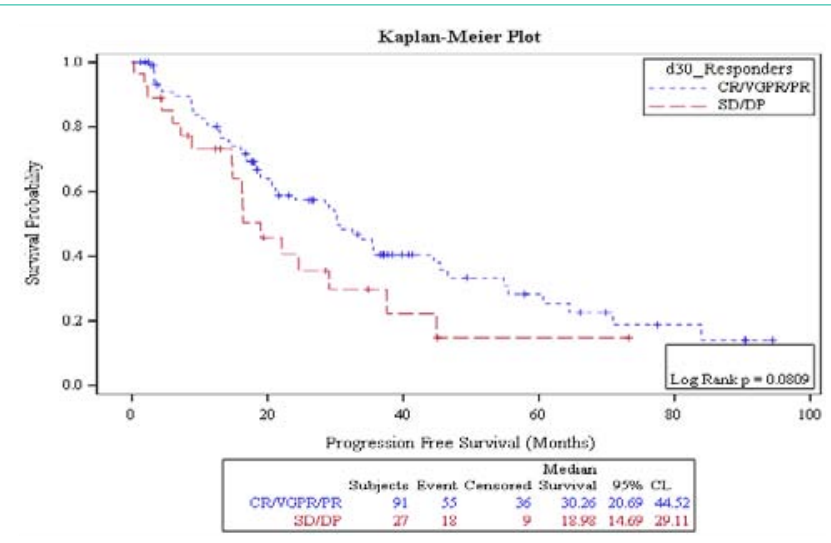

Figure 4: Day 30 response: PFS in patients achieving Response vs. no response.

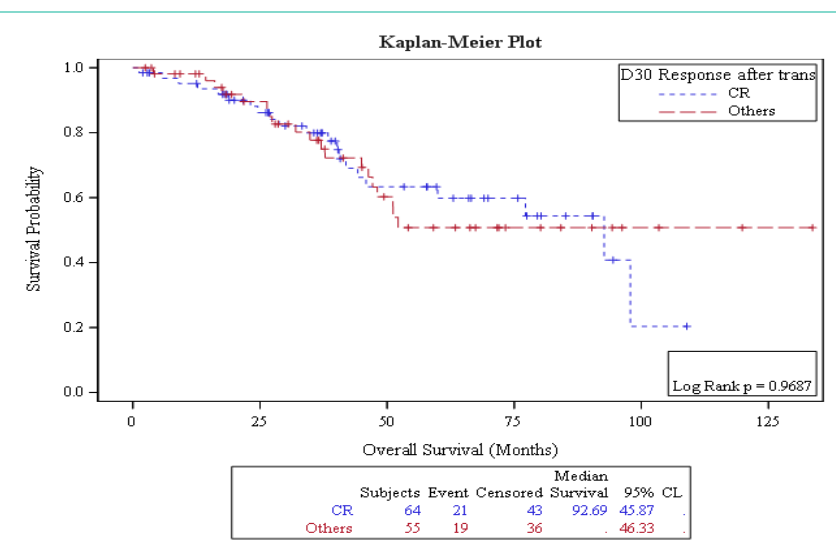

Figure 5: Day 30 response: OS in patients achieving CR vs. no CR.

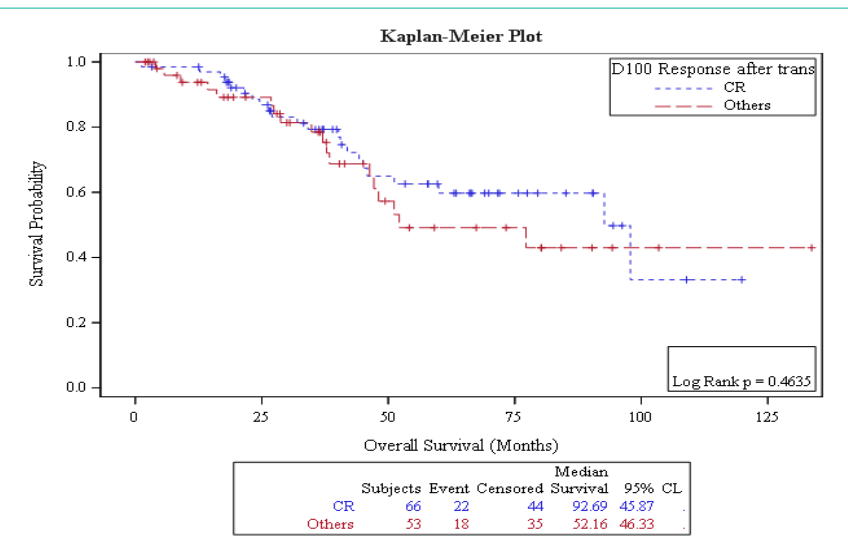

Figure 6: Day100 response: OS in patients achieving CR vs. no CR.

and on D100: 92.6 months vs. not reached, P: 0.887 (Figure 8).

\section{Discussion}

HDC and ASCT is still an important step in the management of transplant eligible MM patients [14.15]. Guidelines from American Society of Bone Marrow Transplant recommend response evaluation 60-90 days after transplant [16].

Currently, HDC and ASCT in multiple myeloma represents one step in the overall plan of care that may be followed with tandem

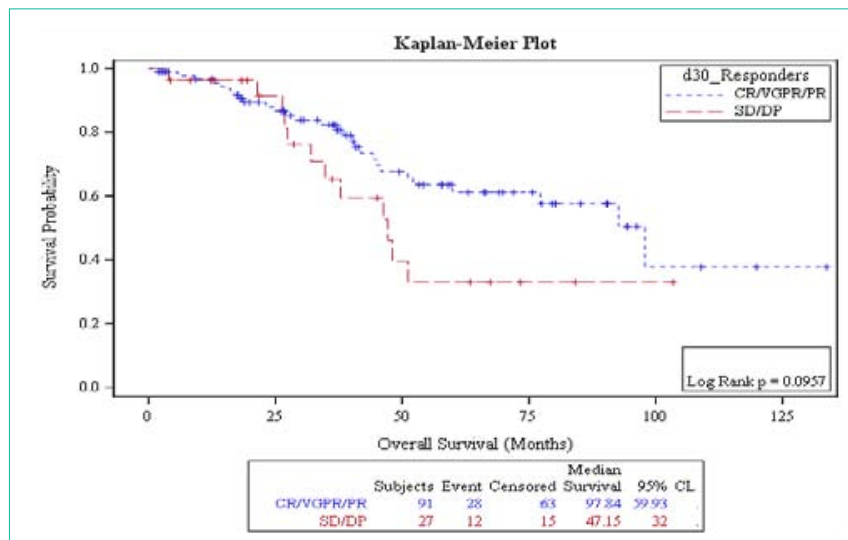

Figure 7: Day 30 response: OS in patients achieving Response vs. no response.

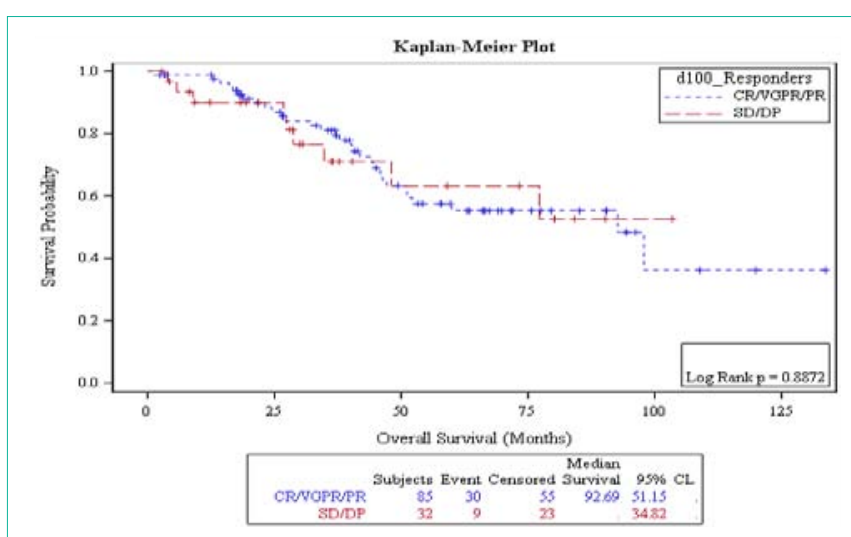

Figure 8: Day 100 response: OS in patients achieving Response vs. no response.

SCT, consolidation and/or maintenance treatment $[17,18]$. Type and depth of response after HDC and ASCT may have important role in consideration of these treatments.

The results of our study were consistent with most of the previously published data on the benefits of HDC and ASCT including increasing CR rates by $14.3 \%$ (from $41.2 \%$ to $55.5 \%$ ) and PFS of 30 months.

Our data show that response may change on day 100 compared to day 30 after ASCT in about $33 \%$ of patients; better response in half of patients and worse in the other half. As we found that D100 evaluation was better predictive of PFS, adoption of further treatment based on early response evaluation should be avoided.

A possible explanation for our findings that B cell and polyclonal immune reconstitution may take up to 1 years after ASCT $[19,20]$. Polyclonal humoral response correlates with PFS and OS suggesting that there may be a competition between the polyclonal $\mathrm{B}$ cells and bone marrow plasma cells [21]. This may explain delayed responses observed in our study.

On the other hand, the presence of oligoclonal humoral response resulting in the appearance in $\mathrm{M}$ protein that is different from that observed on diagnosis which can be detected by immunofixation rather than SPEP is well characterized after HDC and ASCT [22]. This may cause a spike in the M protein that can be misinterpreted 
as disease progression. This phenomenon may be transient [23] and may contribute to difference in response over time after transplant.

Oligoclonal humoral response may be associated with better PFS and OS, as it may result from stronger immune reconstitution [24] This may also support the theory that immune responses contribute to disease control MM after transplant.

For patients with no progression after ASCT, lenalidomide maintenance treatment started within 6 months may help in deepening the response, prolongation of PFS and possibly OS [17-19] As these benefits were more pronounced in patients not achieving CR after ASCT [25], the prognostic significance of better response and the best time for response evaluation may change in maintenance era.

However, our study has important shortcomings including retrospective nature and the lack cytogenetic risk stratification.

Recently, Minimal Residual Disease (MRD) detection using flowcytometry and gene sequencing as well as detection of extramedullary disease with Fluoro-2-Deoxyglucose Positron Emission Tomography (FDG-PET)/Computed Tomography (CT) were incorporated in treatment selection, new drug development and response assessment in multiple myeloma [26-28]. Accordingly, new response categories were included to further stratify complete responders and possibly help in better selection of future therapies.

In conclusion, patients with multiple myeloma receiving HDC and ASCT, response evaluation on D100 better correlated with PFS than D30, and clinical decisions on further treatment can be delayed.

\section{Acknowledgments}

Mrs. Ayat Taqash, office of scientific research, King Hussein Cancer Center, Amman, Jordan.

\section{References}

1. Attal M, Harousseau JL, Stoppa AM, Sotto JJ, Fuzibet JG, Rossi JF, et al A prospective, randomized trial of autologous bone marrow transplantation and chemotherapy in multiple myeloma. Intergroupe Francais du Myelome. N Engl J Med. 1996; 335: 91-97.

2. Child JA, Morgan GJ, Davies FE, Owen RG, Bell SE, Hawkins K, et al. High-dose chemotherapy with hematopoietic stem-cell rescue for multiple myeloma. N Engl J Med. 2003; 348: 1875-1883.

3. Palumbo A, Cavallo F, Gay F, Di Raimondo F, Ben Yehuda D, Petrucci MT, et al. Autologous transplantation and maintenance therapy in multiple myeloma. N Engl J Med. 2014; 371: 895-905.

4. Koreth J, Cutler CS, Djulbegovic B, Behl R, Schlossman RL, Munshi NC et al. "High-dose therapy with single autologous transplantation versus chemotherapy for newly diagnosed multiple myeloma: a systematic review and meta-analysis of randomized controlled trials," Biology of Blood and Marrow Transplantation. 2007; 13: 183-196.

5. van de Velde HJ, Liu X, Chen G, Cakana A, Deraedt W, Bayssas M. Complete response correlates with long-term survival and progression-free survival in high-dose therapy in multiple myeloma." Haematologica. 2007; 92 : 1399-1407.

6. Martinez-Lopez J, Blade J, Mateos MV, Grande C, Alegre A, García-Laraña $\mathrm{J}$, et al. Long-term prognostic significance of response in multiple myeloma after stem cell transplantation. Blood. 2011; 118: 529-534.

7. Lahuerta JJ, Mateos MV, Martínez-López J, Rosiñol L, Sureda A, de la Rubia $\mathrm{J}$, et al. Influence of pre- and post-transplantation responses on outcome of patients with multiple myeloma: sequential improvement of response and achievement of complete response are associated with longer survival.
Journal of Clinical Oncology. 2008; 26: 35.

8. Palumbo A, Bringhen S, Petrucci MT, Musto P, Rossini F, Nunzi M, et al Intermediate-dose melphalan improves survival of myeloma patients aged 50 to 70: results of a randomized controlled trial. Blood. 2004; 104: 3052.

9. Moreau $\mathrm{P}$, Avet-Loiseau $\mathrm{H}$, Facon $\mathrm{T}$, Attal $\mathrm{M}$, Tiab $\mathrm{M}$, Hulin $\mathrm{C}$, et al Bortezomib plus dexamethasone versus reduced-dose bortezomib, thalidomide plus dexamethasone as induction treatment before autologous stem cell transplantation in newly diagnosed multiple myeloma. Blood. 2011; 118: 22.

10. Kumar L, Cyriac SL, Tejomurtula TV, Bahl A, Biswas B, Sahoo RK, et al. Autologous Stem Cell Transplantation forMultiple Myeloma: Identification of Prognostic Factors Clinical Lymphoma, Myeloma \& Leukemia. 2013; 13: 3241

11. Barlogie B, Tricot G, Anaissie E, Shaughenessy J, Rasmussen E, Van Rhee, et al. Thalidomide and hematopoietic-cell transplantation for multiple myeloma. N Engl J Med. 2006.

12. Kyle RA, Durie BG, Rajkumar SV, Landgren O, Blade J, Merlini G, et al. Monoclonal Gammopathy of Undetermined Significance (MGUS) and smoldering (asymptomatic) multiple myeloma: IMWG consensus perspectives risk factors for progression and guidelines for monitoring and management. Leukemia. 2010; 24: 1121-1127.

13. Greipp PR, San Miguel J, Durie BG, Crowley JJ, Barlogie B, Bladé J, et al. International staging system for multiple myeloma. J Clin Oncol. 2005; 23: 3412-3420

14. National Comprehensive Cancer Network, Clinical Practice Guidelines for management of Multiple Myeloma, version 3, 2020.

15. Gavriatopoulou M, Musto P, Caers J, Merlini G, Kastritis E, van de Donk $\mathrm{N}$, et al. European myeloma network recommendations on diagnosis and management of patients with rare plasma cell dyscrasias. Leukemia. 2018; 32: $1883-1898$.

16. Shah N, Callander N, Ganguly S, Gul Z, Hamadani M, Costa L, et al. Hematopoietic Stem Cell Transplantation for Multiple Myeloma: Guidelines from the American Society for Blood and Marrow Transplantation. Biol Blood Marrow Transplant. 2015; 21: 1155-1166.

17. Attal M, Lawers-Cances V, Marit G, Richardson PG, Hulin C, Tosi P, et al. Lenalidomide maintenance after stem-cell transplantation for multiple myeloma. N Engl J Med. 2012; 366: 1782-1791.

18. McCarthy PL, Holstein SA, Petrucci MT, Richardson PG, Hulin C, Tosi P, et al. Lenalidomide Maintenance After Autologous Stem-Cell Transplantation in Newly Diagnosed Multiple Myeloma: A Meta-Analysis. J Clin Oncol. 2017; 10: $3279-3289$

19. Hernandez MD, delCanizo MC, Gonzalez M, Caballero MD, López-Berges MC, Vázquez L, et al. Immune reconstitution after autologous progenitor hemopoietic cell transplantation. A study comparing autologous bone marrow and autologous peripheral blood transplantation. Med Clin (Barc). 1998; 110: 768-773.

20. González-Calle V, Cerdá S, Labrador J, Sobejano E, González-Mena B, Aguilera C, et al. Recovery of polyclonal immunoglobulins one year after autologous stem cell transplantation as a long-term predictor marker of progression and survival in multiple myeloma. Haematologica. 2017; 102: 922-931.

21. Rueff J, Medinger M, Heim D, Passweg J, Stern M. Lymphocyte subset recovery and outcome after autologous hematopoietic stem cell transplantation for plasma cell myeloma. Biol Blood Marrow Transplant. 2014; 20: 896-899.

22. Tovar N, de Larrea CF, Aróstegui JI, Cibeira MT, Rosiñol L, Rovira M, et al Natural history and prognostic impact of oligoclonal humoral response in patients with multiple myeloma after autologous stem cell transplantation: long-term results from a single institution. Haematologica. 2013; 98: 11421146.

23. Zent CS, Wilson CS, Tricot G, Jagannath S, Siegel D, Desikan KR, et al Oligoclonal protein bands and $\mathrm{Ig}$ isotype switching in multiple myeloma treated with high-dose therapy and hematopoietic cell transplantation. Blood. 
1998; 91: 3518-3523.

24. Lonial S, Anderson KC. Association of response endpoints with survival outcomes in multiple myeloma. Leukemia. 2014; 28: 258-268.

25. Yanamandra U, Kumar SK. Minimal residual disease analysis in myeloma when, why and where. Leuk Lymphoma. 2018; 59: 1772-1784.

26. Cavo M, Terpos E, Nanni C, Moreau P, Lentzsch S, Zweegman S, et al Role of 18F-FDG positron emmission tomography/computed tomography in the diagnosis and management of multiple myeloma and other plasma cell dyscrasias: a consensus statement by the International Myeloma Working Group. Lancet Oncol. 2017; 18: e206-e217.
27. Paiva B, van Dongen JJ, Orfao A. New criteria for response assessment: role of minimal residual disease in multiple myeloma. Blood. 2015; 125: 3059 3068.

28. Kumar S, Paiva B, Anderson KC, Durie B, Landgren O, Moreau P, et al International Myeloma Working Group consensus criteria for response and minimal residual disease assessment in multiple myeloma. Lancet Oncol. 2016; 17: 328-346. 